\title{
Prototype Business Models for Mobility-as-a-Service
}

Amalia Polydoropoulou ${ }^{1}$, Ioanna Pagoni ${ }^{1, *}$, Athena Tsirimpa ${ }^{1}$, Athena Roumboutsos ${ }^{1}$, Maria Kamargianni ${ }^{2}$, Ioannis Tsouros ${ }^{1}$

${ }^{1}$ Department of Shipping, Trade and Transport, University of the Aegean, Chios, Greece

${ }^{2}$ MaaSLab, Energy Institute, University College London,14 Upper Woburn Place,

WC1H0NN, London, UK.

* Corresponding Author (email: ipagoni@ aegean.gr)

\section{Declarations of interest: none}




\begin{abstract}
Mobility as a Service (MaaS) is a promising concept which aims at offering seamless mobility to end users and providing economic, societal, transport-related and environmental benefits to the cities of the future. To achieve a successful future market take-up of MaaS it is important to develop prototype business models to offer high-value bundled mobility services to customers, as well as enable the MaaS operator and the involved actors to capture value. This paper aims at investigating the business perspective of MaaS by collecting qualitative data from workshops and in-depth interviews in three European metropolitan areas: Budapest, Greater Manchester and the city of Luxembourg. The analysis of the collected data contributed to the in-depth analysis of the MaaS business ecosystem and the identification of the champions of MaaS in the three areas. Prototype business models for MaaS are developed based on the Osterwalder's canvas, to describe how MaaS operators may create, deliver, and capture value. Our findings indicate that the MaaS ecosystem comprises of public and private actors who need to cooperate and compete in order to capture value. Although noticeable deviations among the study areas are observed, mobility service providers, public transport authorities and regional authorities were commonly indicated as the key actors in a MaaS partnership. In addition, viewed as a system, enablers and barriers to MaaS are identified based on the systems' of innovation approach. The analysis indicates that the regulatory framework of the cities, the lack of standardization and openness of the application programming interfaces and the need for transport-related investments constitute risks for the successful implementation of MaaS in the study areas. Trust between MaaS actors and cooperation in e-ticketing are key enablers in some of the study areas.
\end{abstract}

Keywords: Mobility as a Service; Business Model Canvas; Value proposition; MaaS ecosystem; enablers and barriers to MaaS. 


\section{Introduction}

The rapid advancement of technology and innovation in transportation has resulted in the emergence of various new transport modes and mobility services which aim to address the issues of traffic congestion, accessibility, air pollution, energy use and social inclusion (EC, 2017a; Sprei, 2018). The synchronization of these new forms of urban mobility with the traditional transport modes that are currently in place could contribute to the sustainability of the urban environment (Ma et al., 2018; Polis, 2017; Hietanen, 2014). Within this rationale, Mobility-as-a-Service (MaaS) is a user-centric, intelligent mobility management and distribution system. The MaaS system integrator brings together the offerings of the multiple mobility service providers, through a digital interface, allowing end users to seamlessly plan and pay for mobility (MaaSLab, 2018; Hietanen, 2014; Kamargianni \& Matyas, 2017).

The above terminology makes it clear that MaaS implementation requires the combination of several transport modes and services, including public transport, taxi, car rentals (traditional transport modes) and emerging transport options (e.g. autonomous vehicles, bike- and carsharing, ride hailing, carpooling, etc.) (Transport Systems Catapult, 2016; EC, 2017a), while integrating some key components such as booking, ticketing and multimodal traveler information services (König et al., 2016). Enabling cities to transform their current mobility towards MaaS requires a number of aspects to be considered and addressed, including meeting operational and technical requirements and, most importantly, business viability.

The success of MaaS significantly depends on understanding the unique particularities of each implementation area so as to design appropriate business models which are capable of providing the necessary business viability to the involved actors while flexibly responding to the cities' and end users' needs. These models need to take into account the MaaS operator's mission, objectives and strategy. In addition, other aspects that need to be considered include: (i) the current and foreseeable transport landscape of each implementation area (i.e. existing or planned mobility services in a city, transportation-related technological achievements of the area, etc.); (ii) the actors originating from different sectors, i.e. transport and information technology (IT) sector, and their potential partnership within MaaS; (iii) the new sources of revenue and new cost structure within the MaaS scheme; and (iv) the opportunities as well as the potential barriers to MaaS implementation and how these are differentiated. The above demonstrate that, to implement a MaaS business model in a specific city or region, customization may be required to address local network externalities and the underlying conditions of the market the MaaS operator serves.

The purpose of this paper is twofold. The first aim is to define the MaaS business ecosystem and explore the value proposition created by the implementation of MaaS in three European metropolitan areas. Specifically, the following study areas are considered: i) Budapest, Hungary (BUD); ii) Greater Manchester, United Kingdom (GM); and iii) Luxembourg city, Luxembourg (LUX). In each of the examined business ecosystems, the importance of the different MaaS actors and their role in creating value within the MaaS partnership is assessed. The second objective is to design a prototype business model for MaaS and investigate whether and how it should be customized for its successful take-up in different cities after specifying their characteristics and identifying the potential opportunities and barriers. For this purpose, data from stakeholders were obtained via workshops and in-depth interviews as part of the EC$\mathrm{H} 2020$ funded project MaaS4EU ${ }^{1}$. The contribution of our paper lies in the following advances to the state-of-the-art. First, we develop a generic prototype business model for MaaS using the Osterwalder's canvas to consider the full potential of the ideal MaaS. Second, we conduct an analysis of the systemic enablers and barriers of MaaS based on the systems of innovation

\footnotetext{
${ }^{1}$ www.maas4eu.eu
} 
framework (Woolthuis et al., 2005; Roumboutsos et al., 2014) in the three study areas. The above reveals the factors that may, in some cases, change the way a MaaS operator conducts its business and should be considered when implementing a business model for MaaS. Finally, the generic business model canvas is customized for each study area to provide city-specific prototype business models for MaaS. Our analysis will deliver knowledge to various stakeholders as follows: (i) MaaS operators, who plan to develop a MaaS scheme, by employing the generic business model components to support their decision making, as well as to motivate mobility service providers to offer specialized services; (ii) MaaS partners, who could consider the proposed business model prototype when planning to participate in a MaS scheme; (iii) city governments, considering to implement a MaaS scheme in their city, who could consider the opportunities and challenges identified to promote related investments, develop future transport policies and potentially use MaaS as a travel demand management tool.

\section{Background}

Although MaaS has recently emerged, a number of applications have already been developed the past years in Europe and worldwide, showing a rapidly growing market. From the first pilot of UbiGo in 2014 in Gothenburg, Sweden and the subsequent launch of Whim in 2016 in Helsinki, Finland (Karlsson et al., 2016; Smith et al., 2018), several MaaS initiatives have been implemented worldwide. Switchh in Hamburg, Tuup in Turku, EMMA in Montpellier and SkedGo in Australia and New Zealand are some of the MaaS schemes currently operating (Ho et al., 2018; Veerapanane et al., 2018; Ebrahimi et al., 2018; Goodall et al., 2017; Hensher, 2017; Jittrapirom et al., 2017; Nikitas et al., 2017; Kogut and Rapacz, 2015; König et al., 2016; Lane and McGuire, 2014).

MaaS currently builds on the integration of traditional transport modes (i.e. public transit services, taxis) and on-demand services that have recently appeared in the transportation era (i.e. shared mobility concepts) to deliver flexible, seamless and fit-for-purpose mobility. In this way, MaaS provides an alternative to non-public transport users, who might prefer to replace their car with other personalized mobility schemes within the city limits. It, also, introduces a disruptive innovation covering gaps in the urban transit system through the creation of market niches that deliver added-value services for public transport users through personalized mobility schemes (Christensen, 1997; Christensen et al., 2015).

The way MaaS will unfold in the future is still uncertain and depends on a series of technological, social, mobility and regulatory trends and developments. While traditional transportation modes (auto, transit, bicycle) have evolved incrementally, mobility solutions brought about by the sharing economy (i.e. car-sharing, bike-sharing, ride hailing, carpooling etc.), that have substantially disrupted the transport market are expected to grow further (Sprei, 2018). More specifically, car sharing and ride hailing have grown exponentially, gaining a share of urban and suburban mobility market (Shaheen et al., 2016). Current projections indicate significant growth potential of car sharing (CAR, 2016; McKinsey \& Company, 2016) and ride hailing in the near future (Burgstaller et al., 2017), which means that they could form important components of future MaaS. In addition, autonomous vehicles which are expected to gradually enter the market, may have the potential to disrupt the current MaaS concept. Research suggests that autonomous car-sharing and ride hailing schemes will become a reality in the next two decades (Nazari et al., 2018; Litman, 2018) leveraging the benefits of autonomous vehicles on MaaS. Besides, the utilization of new vehicle technologies in MaaS, such as autonomous cars, electric drives and fuel cells, might further deliver environmental benefits (Wadud et al., 2016).

If MaaS evolves into a car-centric solution, this could have an adverse effect on road capacity and increase traffic congestion (Hensher, 2018; Mulley and Kronsell, 2018). Therefore, a critical issue under discussion is the importance of public transport in the delivery of MaaS 
(Hensher, 2017, 2018; Mulley et al., 2018; Utriainen and Pöllänen, 2018). Although the significance of conventional public transport in MaaS has been widely acknowledged, several challenges have been identified regarding the role of stakeholders in the delivery of public transport, the future of public subsidization and the implications of existing regulatory regimes on MaaS. Indeed, transport deregulation and regulatory reform of urban public transport has been a major world trend, due to concerns about the economic performance of public transport. A survey to transportation executives and experts conducted by Oliver Wyman (2016) indicated that liberalization of railways, bus services and taxis will continue to spread, thus, enabling new players to enter the mobility market. In fact, many governments have started exploring private operation or involvement in the management of urban transit systems, due to the increase of government public transport subsidies (Currie, 2016). Similarly to shared mobility, the successful development and implementation of MaaS depends highly on regulation and policies that contribute to innovation (Jittrapirom et al., 2018). Although ride hailers are developing into regional champions in Asia (i.e. Didi in China) and the United States (i.e. Uber and Lyft), existing regulatory issues might challenge the adoption of such new mobility services in Europe (Burgstaller et al., 2017).

Despite the fact that MaaS currently builds on existing technologies and business models, the above discussion reveals that as new players enter the current MaaS business ecosystem, a significant impact on the existing business models of transport operators is expected. The companies involved in MaaS need to adapt their value creation process in order to remain profitable in the changing ecosystem. Creating viable business models for MaaS is crucial to ensure that customers' needs and preferences are met and the cooperation of multiple actors under a unique mobility platform is achieved (Mulley and Kronsell, 2018). However, the development of prototype business models for $\mathrm{MaaS}$ is an under-researched area, as existing literature is mainly limited to: (i) contributions aiming to define the MaaS business ecosystem and specify the actors involved and their roles within the ecosystem (Holmberg et al., 2016; König et al., 2016; Kamargianni and Matyas, 2017) and (ii) contributions which analyze existing schemes and categorize them in different types of MaaS operator models. More specifically, in the context of the research projects "MAASiFiE" and "Rural-MaaS", König et al. (2016), Aapaoja et al. (2017) and Eckhardt et al. (2017) considered various MaaS schemes and pilots (including Tuup, Whim, Ylläs Around, Kutsuplus, UbiGo, etc.) and concluded on four categories of MaaS operator models, i.e. the MaaS operator as a private company, a public transport operator, a public-private partnership (PPP) and a public-private-people partnership (PPPP). Their analysis revealed that the public transport operator-based model would be more common in cities, suburban areas and interurban transport, where public transport plays a vital role in transportation, while the PPP and PPPP models could bring significant benefits for the users in rural areas. Holmberg et al. (2016) presented Ubigo's business model canvas and described the potential role of public transport in a MaaS scheme, as coordinator (MaaS operator) or collaborator (partner), emphasizing on potential barriers to its implementation. Sarasini et al. (2017) identified different ways in which business models for MaaS can generate sustainable value, linked to mobility services, data-based services, environmental technology and material recirculation. Finally, Ebrahimi et al. (2018) presented a classification of business architectures for MaaS based on the integration of the offered mobility services and the (dis)integration of distribution and marketing channels.

The Osterwalder's business model canvas framework has been used in the past by König et al. (2016) to develop a general business model for MaaS, while Romanyuk (2018) based on it developed a business model tha would apply in Finland. The contribution of our paper is the development of a generic prototype business model for MaaS realizing its full potential i.e. including all promising partners, serving all possible customer segments, exploiting all probable resources, etc. However, real-life applications of MaaS business models must address 
and adapt to the local conditions and unique particularities (such as infrastructure/technology, operators' capabilities, regulatory issues, social values). This paper addresses this challenge by identifying commonalities and differences in three European metropolitan areas via workshops and in-depth interviews revealing how the developed business model should be customized for its successful deployment.

\section{Research Approach}

In order to achieve the objectives of this paper, a combination of different research methods is employed, as illustrated in Figure 1. A literature review is conducted regarding the business perspective of MaaS and other innovative transport concepts, such as shared mobility. The information acquired by this review is then supplemented by qualitative data collected from stakeholders in three European areas via workshops and interviews. The analysis of this data enables (i) the identification of the most important MaaS actors and their roles (business ecosystem approach), (ii) the mapping of the unique characteristics and imperfections of each area (systems of innovation approach) and (iii) the development of a generic prototype business model for Maas based on Osterwalder's business model canvas. The systems' of innovation framework is applied to analyze the opportunities and challenges of the three study areas and provide insights on the factors that should be considered when implementing a city-specific business model for MaaS. In this way, the generic canvas is customized to provide prototype business models for the three study areas.

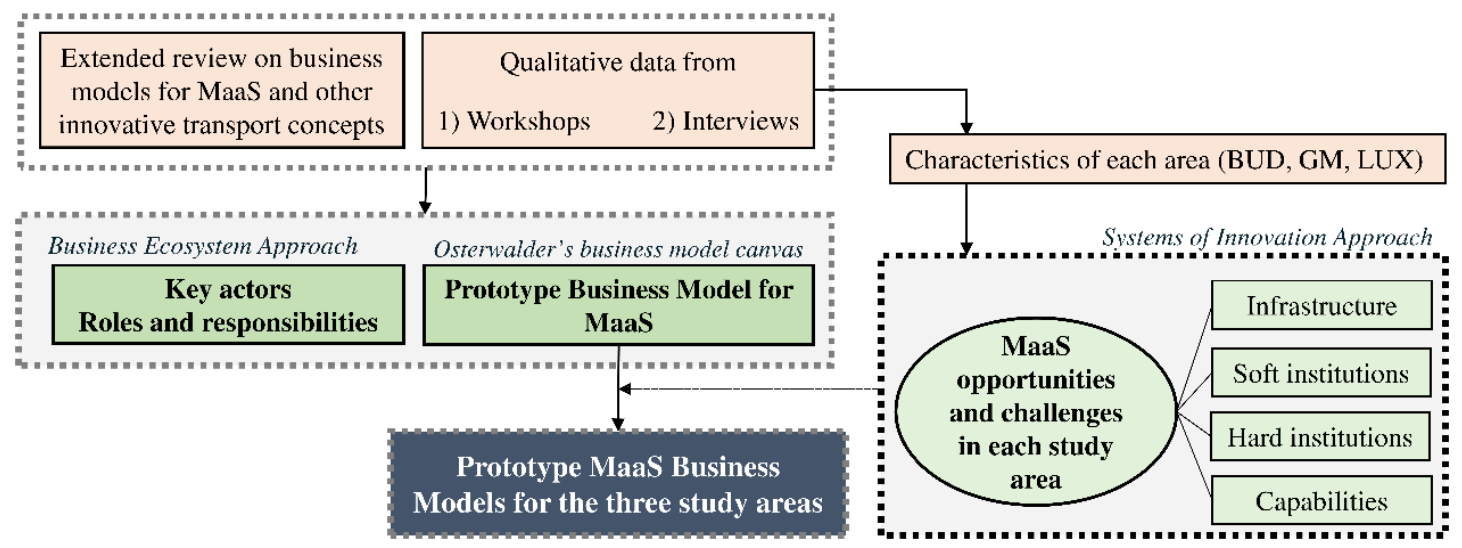

Figure 1. Research Approach

The business model is seen as a tool for depicting and evaluating the business logics in both new and existing organizations (Veit et al., 2014) and has especially gained prominence among both practitioners and academics with the emergence of information and communication technologies and internet companies (DaSilva and Trkma, 2014). Although there is a considerable number of papers defining business models, no unique definition is accepted for the term Business Model (Morris et al., 2005; Zott et al., 2011; Weil et al., 2011). Based on Amit and Zott (2001), a business model depicts "the content, structure, and governance of transactions designed so as to create value through the exploitation of business opportunities", while Magretta (2002) defines business models as "stories that explain how enterprises work". In a more general view, "the business model describes the design or architecture of the value creation, delivery, and capture mechanisms a firm employs" (Teece, 2018). Although even more definitions have been proposed in the past (Arend, 2013; Morris et al., 2005; Shafer et al., 2005; Zott et al., 2011), the framework proposed by Osterwalder et al. (2005) is mostly used by researchers and practitioners for the description, analysis and design of a business model. For this reason, it is employed to develop the MaaS business model. The nine building blocks of the business model, namely key partners, key activities, key resources, value propositions, 
customer relationships, channels, customer segments, cost structure and revenue streams (Osterwalder \& Pigneur, 2010) are specifically analyzed (see Section 5.2).

\subsection{Study areas}

Our analysis concerns three European metropolitan areas: Budapest, Hungary (BUD); Greater Manchester, United Kingdom (GM); and Luxembourg city, Luxembourg (LUX). These areas have been selected so as to explore how the deployment of MaaS and its business perspective might emerge among different cities. As presented in Table 1 and described below, several factors and city-specific particularities motivated the selection of these study areas: the wide geographical coverage; the different socioeconomic characteristics and mobility patterns of citizens; the different levels of public transport regulation; the different levels of interest in MaaS among the cities. Finally, as indicated in Table 1, a wide variety of mobility services (e.g. public transport, sharing schemes, taxi) are available in the study areas and could contribute to the materialization of MaaS.

Budapest is the capital of Hungary, located in Eastern Europe, and has a population of 1.73 million inhabitants (based on the 2011 Census data; HCSO, 2011). Hungary has the lowest per capita gross domestic product (GDP) in comparison to the other selected study areas (ranked $27^{\text {th }}$ in Europe with $\$ 28,799$ in 2017; OECD, 2018a). However, Budapest is considered as a growing economy and has been ranked as the second fastest-developing urban economy in Europe, with an increase of $2.4 \%$ in the gross domestic product per capita and $4.7 \%$ increase in employment for 2014 (Parilla et al., 2014). Stakeholders in Budapest had expressed strong interest to implement MaaS in their city. In fact, current citizens' mobility patterns indicate that the majority of the trips within Budapest are conducted by public transport (45\% of total trips), while $35 \%$ and $20 \%$ are conducted by car and active transport modes respectively (Juhász et al., 2014). In addition, since 2010, with the establishment of the new, integrated transport management model and the BKK Centre for Budapest Transport, a multimodal development approach promoting public transport and cycling infrastructure projects was introduced. Therefore, in Budapest, MaaS would further encourage multimodality by combining public transport modes with private vehicles.

Greater Manchester is a city of the United Kingdom, located in Northern Europe and has a population of 2.7 million people. In 2017, U.K. was the $14^{\text {th }}$ European country in terms of GDP per capita with $\$ 44,909$ (OECD, 2018b). Based on the most recent statistics, its residents are highly dependent on private vehicles for their trips. More specifically, in 2016 most residents (about $70 \%$ ) commuted to work by private vehicles, while each individual conducted 575 (out of 921) annual trips by car (Transport for Greater Manchester, 2018). Greater Manchester is a highly relevant case study for MaaS given its current high levels of car usage, despite significant levels of investment in public transport. Moreover, Greater Manchester has shown strong interest in MaaS and has established collaborations with several projects and networks so far to promote new mobility services including MaaS, autonomous vehicles and bike sharing schemes. Finally, it is an ideal policy test-bed, given the current deregulated nature of its bus market, since all bus services in the United Kingdom outside London are deregulated.

Luxembourg city is a city located in Central Europe, with a population of more than 114 thousand residents (STATEC, 2017). Luxembourg is considered one of the richest countries in Europe, with GDP per capita of $\$ 107,525$ in 2017 (OECD, 2018c). The majority of the national trips are conducted by car (82.9\% of 2015 total trips; EC, 2017b). Luxembourg city is a special case since a considerable percentage of the city's employees ( $42 \%$ of the workforce) live in neighboring countries (Belgium, Germany and France) due to the high cost of living in the country (OECD, 2016) and conduct cross-border trips mainly by car on a daily basis. Thus, MaaS could contribute to the decrease of car usage and promote alternatives offerings for cross- 
border trips. Luxembourg City Council and mobility service providers located in the region, initially, had a weak interest for MaaS. The recent publicly expressed interest of the Ministry of Transport intrigued the mobility service providers to participate in the MaaS concept.

Table 1. Main characteristics of the three study areas

\begin{tabular}{|c|c|c|c|}
\hline & Budapest & Greater Manchester & Luxembourg city \\
\hline Location & Eastern Europe & Northern Europe & Central Europe \\
\hline Population & 1.73 million & 2.7 million & 0.11 million \\
\hline \multicolumn{4}{|c|}{ Country's economic indicators } \\
\hline - GDP per capita & $\$ 28,799$ & $\$ 44,909$ & $\$ 107,525$ \\
\hline - Average wage & $\$ 22,576$ & $\$ 43,732$ & $\$ 63,062$ \\
\hline Modal split & $\begin{array}{l}\text { High public } \\
\text { transport usage }\end{array}$ & $\begin{array}{c}\text { High private car } \\
\text { usage }\end{array}$ & $\begin{array}{l}\text { High private car usage } \\
\text { for cross-border trips }\end{array}$ \\
\hline Public transport regulation & $\begin{array}{l}\text { Public transport } \\
\text { regulated }\end{array}$ & $\begin{array}{c}\text { Public transport } \\
\text { deregulated }\end{array}$ & $\begin{array}{l}\text { Public transport } \\
\text { regulated }\end{array}$ \\
\hline \multicolumn{4}{|c|}{ Availability of mobility services* } \\
\hline $\begin{array}{l}\text {-Public Transport } \\
\text { authority }\end{array}$ & 1 & 1 & 1 \\
\hline -Bus operators & 1 & 6 & 4 \\
\hline -Tram operators & 1 & 1 & 1 \\
\hline - Railway operators & 1 & 4 & 1 \\
\hline - Bike sharing operators & 1 & 6 & 1 \\
\hline - Car sharing operators & 2 & 3 & 3 \\
\hline - Car pooling apps & 1 & 3 & 1 \\
\hline - Taxi providers & 3 & 4 & 4 \\
\hline - Other transport operators & $\begin{array}{l}\text { Several car hire } \\
\text { companies }\end{array}$ & $\begin{array}{c}\text { Several car hire } \\
\text { companies; } 1 \text { coach } \\
\text { hire company }\end{array}$ & $\begin{array}{c}\text { Several car hire } \\
\text { companies; scooters; } \\
\text { shuttle buses }\end{array}$ \\
\hline
\end{tabular}

\subsection{Data}

To collect the data from the stakeholders, three workshops and four in-depth interviews were conducted in the three study areas. The workshops were organized in round-table discussions, where the participants were asked to address and discuss a structured questionnaire regarding several aspects of MaaS, including the business perspective. Stakeholders were allocated to round tables so as to ensure representation of different actors in the respective discussions. The workshops provided the stakeholders' viewpoints regarding MaaS's most important actors; anticipated benefits; most appropriate revenue distribution models; financing and funding sources; targeted end users and ways to approach them; as well as barriers to MaaS implementation. In addition, stakeholders were asked to express their viewpoints on different business models with diversifying MaaS operators and organizational structures and to specify the nine building blocks of a MaaS business model canvas for their city. A detailed analysis of the questions asked and the main findings of the workshops can be found in Polydoropoulou et al. (2019). The workshop in Budapest gathered 39 stakeholders, while the workshops in Greater Manchester and Luxembourg gathered 51 and 28 participants respectively. The synthesis of participating stakeholders in the workshops was decided with the aim to cover a wide range of MaaS actors taking into consideration the MaaS ecosystem actors identified in a previous study conducted by Kamargianni and Matyas (2017). As indicated in Table 2, different MaaS-related actors were represented in each city, including public authorities (transport or government/local authorities), public and private transport operators, information technology (IT) and data companies, research organizations and institutes, transport consultants, financing companies and passenger associations. The majority of the participants were representatives of public and private transport operators (39\% in BUD, 30\% in GM and 41\% in LUX), followed by research 
organizations and universities (26\% in BUD, 23\% in GM and 23\% in LUX), transport consulting companies (9\% in BUD, $19 \%$ in GM and $8 \%$ in LUX), and, finally, IT and data companies $(6 \%, 15 \%$ and $8 \%$ in BUD, GM and LUX respectively). The detailed list of the workshops' participants is presented in Tsirimpa et al. (2018).

Table 2. Type and number of entities involved in the workshops

\begin{tabular}{|c|c|c|c|}
\hline $\begin{array}{l}\text { Type of } \\
\text { entity }\end{array}$ & Budapest & Greater Manchester & Luxembourg city \\
\hline $\begin{array}{l}\text { Public } \\
\text { authorities }\end{array}$ & $\begin{array}{l}1 \text { Public Transport } \\
\text { Authority } \\
1 \text { Local Authority } \\
1 \text { Governmental } \\
\text { Authority }\end{array}$ & $\begin{array}{l}1 \text { Public Transport } \\
\text { Authority } \\
1 \text { Local Authority }\end{array}$ & $\begin{array}{l}1 \text { Public Transport } \\
\text { Authority } \\
2 \text { Local Authorities } \\
1 \text { Governmental } \\
\text { Authority }\end{array}$ \\
\hline $\begin{array}{l}\text { Transport } \\
\text { operators }\end{array}$ & $\begin{array}{l}1 \text { MaaS company } \\
1 \text { public transport } \\
\text { operator } \\
1 \text { taxi provider } \\
1 \text { railway operator } \\
1 \text { carpooling company } \\
2 \text { car-sharing operators }\end{array}$ & $\begin{array}{c}3 \text { bus operators } \\
1 \text { tram operator } \\
1 \text { bike-sharing operator } \\
2 \text { car-sharing operators } \\
1 \text { car rental company } \\
2 \text { railway operators } \\
2 \text { taxi providers } \\
1 \text { shuttle bus operator }\end{array}$ & $\begin{array}{c}1 \text { bus operator } \\
1 \text { bike-sharing operator } \\
1 \text { car rental company }\end{array}$ \\
\hline $\begin{array}{l}\text { IT and data } \\
\text { companies }\end{array}$ & 2 companies & 5 companies & 1 company \\
\hline $\begin{array}{l}\text { Research } \\
\text { institutes/ } \\
\text { Universities }\end{array}$ & $\begin{array}{l}3 \text { universities } \\
1 \text { research institute }\end{array}$ & $\begin{array}{l}3 \text { universities } \\
1 \text { research institute }\end{array}$ & $\begin{array}{l}4 \text { universities } \\
1 \text { research institute }\end{array}$ \\
\hline $\begin{array}{l}\text { Transport } \\
\text { consulting } \\
\text { companies }\end{array}$ & 3 companies & 4 companies & 4 companies \\
\hline $\begin{array}{l}\text { Other } \\
\text { companies/ } \\
\text { associations }\end{array}$ & $\begin{array}{l}2 \text { energy companies } \\
1 \text { financing company } \\
3 \text { associations }\end{array}$ & - & 1 automotive company \\
\hline
\end{tabular}

The in-depth interviews were conducted with four important actors of the MaaS business ecosystem in the three study areas (e.g. MaaS operators, public transport authorities, etc.) to derive their opinion about critical aspects, challenges and opportunities to be faced when developing the MaaS business model.

\section{Identifying Maas business ecosystem champions}

As already explained, to deliver MaaS, multiple actors are required to cooperate under a unique mobility platform. According to Kamargianni and Matyas (2017), MaaS business ecosystem is "the wider network of firms that influences how the MaaS provider, creates and captures value" and comprises of a wide range of stakeholders including public authorities, public and private transport operators, data providers, IT companies, ticketing and payment service providers, telecommunications, financing companies, institutions, passenger associations, etc. (Kamargianni and Matyas, 2017, König et al., 2016, Transport Systems Catapult, 2016). However, the composition of each ecosystem may be totally different than the aforementioned one due to the different conditions in each study area. The diversifying objectives and strategic goals of the potential MaaS operators, the (un)availability of transport solutions and the (un)willingness of the MaaS actors to cooperate within a MaaS partnership are some of the reasons which may result in different compositions of MaaS business ecosystems.

To understand and define the business ecosystems of potential MaaS schemes in the three study areas, the stakeholders were asked to define the key actors in a MaaS partnership. In specific, 
they were presented with a list of different MaaS actors acknowledging the MaaS ecosystem definition given by the existing literature, while they were asked to define any other actor that they considered to be important in a MaaS scheme. These actors could be part of the MaaS ecosystem either as key partners, contributing to the success of the business via adding value through the provision of their services, or as the MaaS operator, integrating the mobility service providers' offerings and selling the MaaS products to end users. The results are illustrated in Figure 2, where the importance of different types of entities (i.e. public or private transport operators, authorities, governmental entities, etc.) to form the MaaS business ecosystem is ranked in a scale of 1 to 5 where 1 means "not important actor" and 5 "extremely important actor". Overall, it is shown that stakeholders tend to regard the mobility service providers as the most important actors in MaaS and especially the public transport operators in a city/region (i.e. bus, metro, tram, and rail). In Europe, the role and participation of public transport authorities is considered critical for a successful deployment of MaaS, while this does not seem to be the case in the United States where the regulatory and competition environment are different (Pöllänen, 2018; Buehler and Pucher, 2012) and emerging mobility service providers are more likely to be the champions of MaaS (House, 2018). Moreover, MaaS Australia argues that delivering the potential benefits of MaaS requires the public transport to be at the center of $\mathrm{MaaS}$ and be complemented with on-demand transport covering the first and last mile (Hensher, 2018). This approach also prevailed in the workshops and interviews.

More specifically, the importance of city/local governments was emphasized both in the indepth interviews and the workshops, as city/local governments are expected to act as facilitators bringing all the relevant actors around the same table and supporting the market creation. Apart from this, city/local governments could support MaaS through providing the general policy formulation and setting the regulatory framework for transport rules (Polis, 2017; Wong et al., 2019); and incentivizing end users to change their current travel behavior towards the offered MaaS services. Non-mobility entities (e.g. IT companies, institutions, data providers, etc.), were rated lower in comparison with mobility service providers, even though they were identified as important actors in MaaS. This provides an indication of the current perception of $\mathrm{MaaS}$ as a concept that assigns more significance to transport operators (especially public transport operators) than to other MaaS actors, such as data providers, IT companies, who, also, have a vital role in a MaaS partnership.

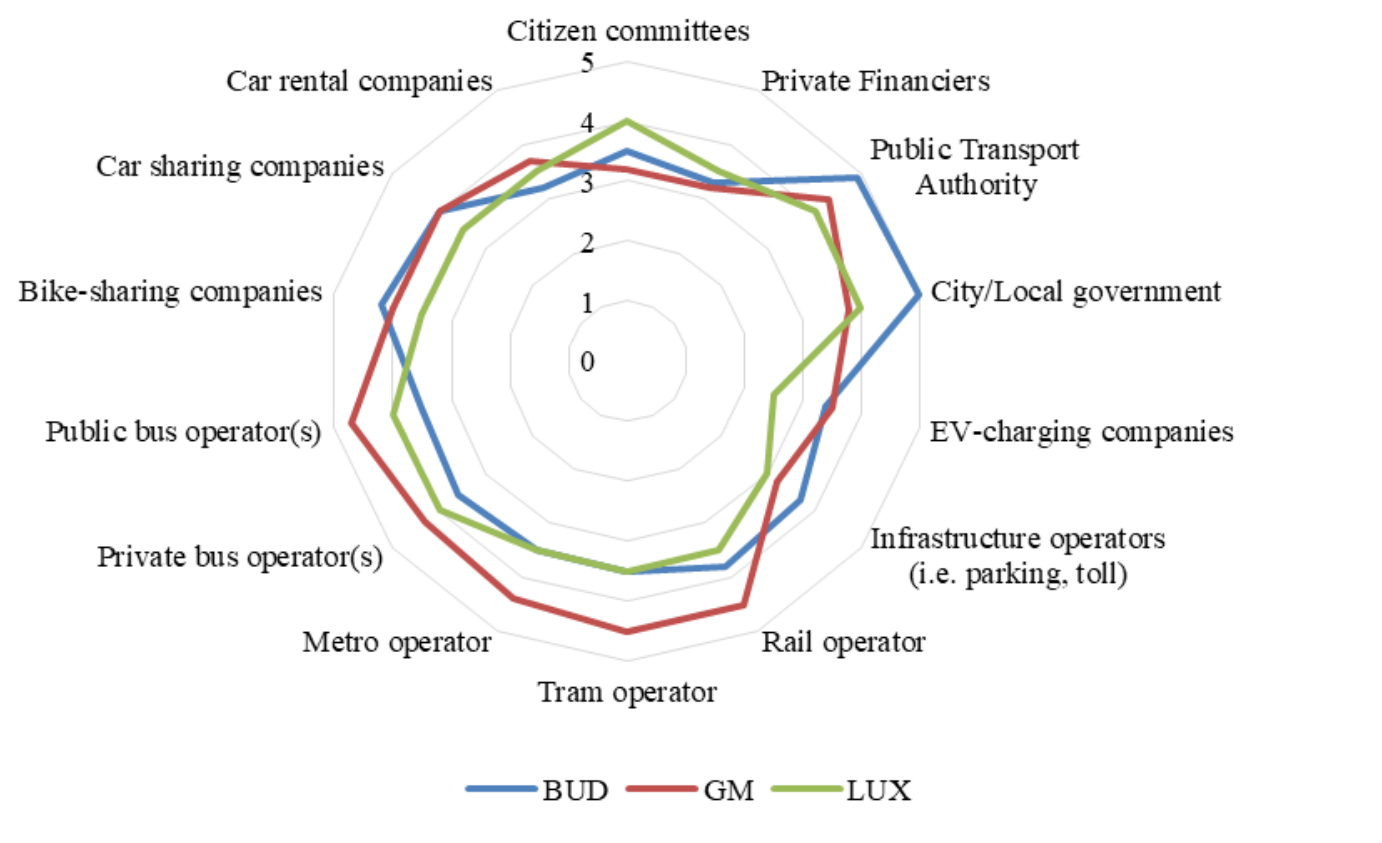

Figure 2. Key actors of the MaaS business ecosystem in the three study areas 
At the heart of the MaaS business ecosystem is the MaaS operator who needs to manage a multi-stakeholder environment. Current state of practice reveals that commercial MaaS developments have been mainly led by private companies with little public authority involvement in the MaaS operator's role. However, the stakeholders' workshops revealed that there is a growing recognition that public transport authorities should take the lead (see Figure 3). It is perceived that the public transport authority which provides the main transportation system of a city/region, i.e. metro, tram, buses and trains, and manages other key MaaS elements (such as scheduling, ticketing, etc.) could deliver a successful MaaS scheme. This finding was expected since public transport entities can built the needed trust with minimal risk compared to a private company. However, as it became evident from the in-depth interviews conducted with public transport authorities in the study areas, they are not willing to undertake such a role because they are lacking the resources needed.

In Budapest, another identified candidate to lead MaaS was a private company dedicated to develop and operate MaaS services. Finally, the option of a private transport operator acting as the MaaS operator was considered as the least appropriate in all study areas. Apart from the aforementioned categories, the stakeholders did not indicate other entities, that could be appropriate to act as the MaaS operator in a city or a wider region, such as companies specialized in multimodal trip planning or road operators.

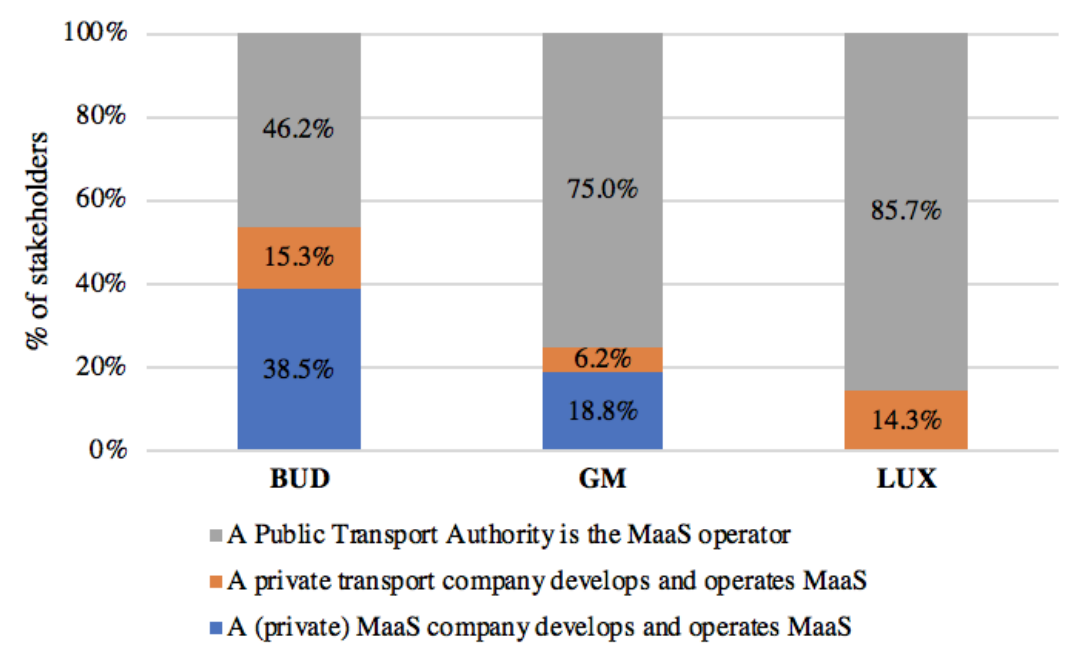

Figure 3. Most appropriate MaaS operators by study area

\section{Prototype business models for MaaS}

This section presents the developed prototype business models for MaaS for the three study areas based on the Osterwalder's business model canvas using the findings from the literature review, the workshops and the in-depth interviews. Special focus is given on the factors that might affect the rationale of how the MaaS operator creates, delivers and captures value in the different cities. For this purpose, the systemic enablers and barriers of MaaS in the three study areas are initially presented.

\subsection{System opportunities and challenges for MaaS implementation}

This section presents the system's opportunities that could enable MaaS implementation and the challenges that might hinder it, as identified via the in-depth interviews and the workshops in each study area. Both perspectives need to be considered when developing a MaaS business model in a city or region. The analysis is based on the rationale of the systems of innovation approach (Woolthuis et al., 2005, Roumboutsos et al., 2014). The system opportunities and 
imperfections in the domains of infrastructure, hard and soft institutions and capabilities are identified and discussed.

Infrastructure: MaaS is a service which requires a number of digital technologies associated with intelligent mobility innovation (ARUP, 2018; Transport Systems Catapult, 2016). First, the MaaS operator should be capable of offering the MaaS products electronically (electronic tickets) (Holmberg et al., 2016). Public transport tickets in Luxembourg and Greater Manchester can be bought online, on the smartphone and in person, which is regarded as an enabler for MaaS implementation. In Budapest, although the public transport authority is discussing the replacement of current paper tickets and passes with card-based electronic ticketing, currently the ticketing system of public transportation relies on paper tickets. This is considered as an infrastructure barrier in Budapest. Another infrastructural issue for MaaS is the availability of open application programming interfaces (APIs) from the different mobility service providers. Availability of APIs and interoperability of systems are prerequisites for the involved actors in a MaaS scheme. However, our analysis reveals that in our study areas few operators have opened their API feeds. More specifically, it was found that in all three areas, APIs regarding journey planning data are open. However, booking, ticketing and pricing data, which are additionally required for MaaS (Transport Systems Catapult, 2016), are opened only by few operators in the three study areas. This may be explained by the unwillingness of some operators to share their data with their competitors.

Hard institutions concern regulatory and legal enablers and barriers faced. For example, the regulatory framework for public transportation in many countries prescribes that no third party is allowed to sell tickets oher than the operator itself (Li and Voege, 2017). In all three areas, pricing for public transport is regulated and thus, MaaS pricing would mean discussions and negotiations between the public authorities and the MaaS operators. In Budapest, a MaaS operator could be able to purchase tickets for its potential customers, but due to the prevailing legal framework, the pass/ticket would be more expensive compared to the one sold to an individual person. This reduces the potential of a MaaS operator to offer competitive prices for its bundled services. Furthermore, discounted tickets (i.e. student and pensioner tickets) cannot be sold by a third party. In addition, in all three study areas the API feeds of some transport operators do not follow compatible data formats and some level of standardization is required. This is, also, considered as a hard institutional barrier for MaaS. However, it is possible that operators might realize the potential benefits of cooperation with respect to "matching" their API feed standards and cooperate in an, otherwise, competitive environment. Hence, the prevailing potential of coopetition (Ritala et al, 2016) arises, as competitors could reap benefits from their collaboration and enable collective value creation.

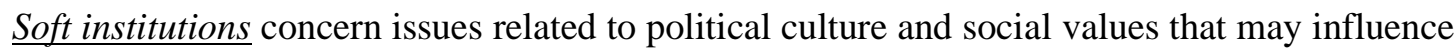
the uptake of MaaS. As already described, residents of Greater Manchester and Luxembourg are highly dependent on private vehicles for their trips, while inhabitants in Budapest mostly use public transport in their everyday life. Thus, from the social perspective, the prevailing car ownership culture in the first two areas is regarded as a soft institutional barrier for MaaS. In addition, in areas where the MaaS scheme offers attractive bundles which include car-related options, such as car sharing, carpooling and ride hailing, there is the risk of leading to a carcentered MaaS scheme, thus, reducing potential social benefits. Trust between the involved MaaS actors is another soft institutional issue for MaaS. Transport operators need to share their data and open APIs feeds to enable the integration of the offered transport services within MaaS. Although this might constitute a threat to the individual operators' business, the in-depth interviews and workshops in Budapest and Greater Manchester indicated that there is a relatively good level of trust between the involved actors. However, in Luxembourg the involvement of small private companies which act as competitors outside MaaS and their 
unwillingness to expose their business models to their competitors was indicated. Finally, the political culture in Budapest would be an institutional barrier for MaaS. The stakeholders who participated in the Budapest workshop stated that the current Hungarian political system and government policy might negatively influence the business prospects of MaaS in their city.

Capabilities: MaaS partners may lack the capacity (resources and financing) to learn rapidly and effectively and, thus, may not be able to make the leap to the technologies embedded in the MaaS concept. This failure was expressed by the interviewee in Luxembourg, who stated that there are many small private operators in Luxembourg, who have the capacities to operate their services but may not have the finances and the human resources to manage an innovationrelated project. This leads to an unwillingness of transport operators to participate in such schemes, although it is acknowledged that MaaS could increase their market and revenues.

Based on the above, Figure 4 presents the observed system enablers and barriers in the three study areas. A range from -3 to +3 is used to depict the level of negative and positive impacts of each study area (average score from the rating assigned to the involved MaaS actors) on the innovation process of MaaS.

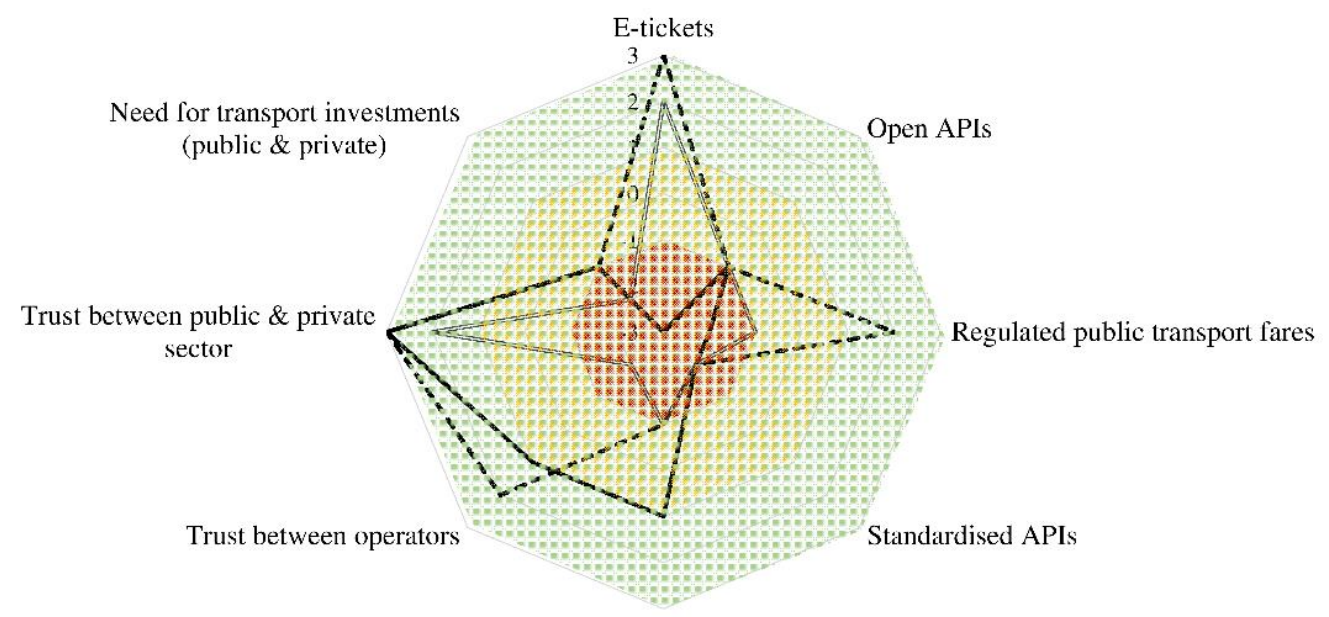

Prevailing car ownership culture

-Budapest ---Greater Manchester $\longrightarrow$ Luxembourg

Figure 4. Systemic enablers and barriers for MaaS in the three study areas

\subsection{Business Model Canvas}

This section describes the strategy the MaaS operator should follow to materialize the ideal $\mathrm{MaaS}$ and offer seamless mobility within a specific region or city. Depending on the type of the MaaS operator and the region/city of MaaS implementation, the rationale of how the MaaS operator creates, delivers and captures value may differ. Therefore, Figures 5 (for Budapest), 6 (for Greater Manchester) and 7 (for Luxembourg city) indicate how the building blocks of the canvas and, thus, the business model changes among the study areas. The elements of the canvas depicted in white correspond to the generic business model for MaaS, which are not currently accounted by the study areas. The city-specific business models have resulted from the combination of the knowledge acquired from the workshops and the in-depth interviews with the MaaS stakeholders in each area. In the following text, the nine building blocks of the MaaS business model canvas are described, while explaining the logic behind their variations in each study area. 
Key Partners: As already described in Section 4, the MaaS ecosystem is built on the interaction of different groups of actors. The main group of the key partners is the mobility service providers, at the core of which is the public transport operators, including bus, tram, train and metro operators. However, shared mobility operators (car sharing, bike sharing, carpooling, ride hailing, etc.), taxi providers and car rental companies, extend the existing public transport network and provide individualized travel solutions leading to the MaaS value proposition (flexible, convenient and sustainable transport with increased accessibility). Regional authorities (i.e. municipalities) are key partners in MaaS as well. In addition, airlines, freight carriers and individuals who wish to share their own vehicles and offer them as a mobility service can be also considered as key partners. MaaS may include car manufacturers, financial transaction enablers and insurance companies. Infrastructure providers could also constitute partners in a MaaS scheme. For example, parking places are needed to enable a MaaS scheme which includes car sharing, bike sharing and carpooling, making parking companies a key partner for MaaS. In addition, a road operator could be a partner in MaaS where additional incentives (i.e. toll discounts etc.) may be given to the customers using car-related service of MaaS (car sharing, carpooling, car rentals). Finally, the MaaS partnership could include research organizations as well as event and entertainment services (when non-mobility services, such as discount coupons or vouchers to be redeemed in stores are offered as part of MaaS). The composition of the key partners in the three study areas is an indication of the potential market interest in MaaS. As it is revealed in Figures 5, 6 and 7 mobility service providers are mostly interested to participate in MaaS. This is also one of the findings of the workshops, where the stakeholders indicated the transport operators as the most important actors in MaaS. In addition, although city/local government were regarded by the workshops' participants as important actors in the MaaS business ecosystem, these entities did not express interest in joining the MaaS partnership in our study areas.

Key activities: To materialize MaaS, a number of activities need to be conducted. The main activity is the development and the provision of the MaaS services, i.e. booking, journey planning, ticketing and payment of the services. Another important activity is customer service to support and assist MaaS customers. In addition, to ensure that customers' needs and preferences are met, the MaaS operator needs to gather, analyze and interpret customer data, as well as feedback provided and ensure that the necessary actions are taken to improve the services provided. Hence, data gathering and processing is a key activity. Also, the processing of real time data concerning travel patterns of the MaaS customers is important, as it leads to a better understanding of the demand side (i.e. origins, destinations, time of travel, mode of transport, use of other services during the trip, etc.) and allows for the provision of route recommendations. Having such kind of data is really important for the MaaS operator since they contribute. As indicated in Figures 5-7, most of these activities are considered as key for the MaaS operators of our study areas. However, due to the infrastructure challenges in Budapest described in Section 5.1, the service provision in this study area is limited to booking and journey planning.

Value Proposition: MaaS is designed in such a way so that all available modes from privatelyowned, shared (car-sharing, bike sharing) and rented vehicles to public transport modes (buses. trams, metros and trains) and taxis (including ride hailing services such as Uber and Lyft) and transport infrastructure (i.e. parking places, etc.) are integrated under a single platform for booking, trip planning, ticketing and payment. Depending on the availability of the different transport modes, MaaS may cover different trip types such as urban, suburban, interurban or cross-border. As already identified by the analysis of the cities' characteristics in Section 3.1, urban and suburban trips are covered by the MaaS operators in Budapest and Greater Manchester, while it was found that MaaS could provide value on serving cross-border trips in the Luxembourg case. The value proposition of MaaS results from the provision of: 
i. Mobility services: The customers can be provided with personalized and customized services, meaning that they can receive specific recommendations and tailor-made plans based on their profile (personalization), while they can modify the offered service option (customization) based on their needs and preferences (Jittrapirom et al., 2017; Hietanen, 2014; Kamargianni et al., 2015). Therefore, end users (individuals and corporate users) experience more convenient, flexible, sustainable and cost-effective trips (ARUP, 2018; Mulley, 2017), while the inclusion of demand-responsive services, such as taxi, Uber, etc. results in improved accessibility. Finally, MaaS can be supplemented with non-mobility services, such as the provision of discount coupons or vouchers to be redeemed in different types of stores (i.e. restaurants, shops, etc.) when sustainable mobility choices are made. With regards to the value proposition of MaaS to the involved actors, our findings from the stakeholders' workshops indicated that it varies depending on the type of the considered MaaS actor (private or public transport operator, parking company, etc.). For private actors, increasing revenues and market share was the main value proposition identified by the stakeholders. Finally, social benefits, such as environmental benefits, public health, reduction of congestion, social equity, etc. constitute other value propositions of MaaS.

ii. Travel-related data: MaaS heavily relies on access and exchange of high-quality data and APIs. In fact, receiving richer data on travel demand patterns and dynamics was indicated as the main value proposition of MaaS for public transport operators. Thus, a potential role of the MaaS operator, who has access to dynamic traffic data (i.e. traffic flows, speed, etc.), could be to provide travel demand management services and forecast travel demand, traffic flows and travel times. This would benefit both the mobility service providers and the MaaS operator, which will be able to provide more precise services, and the travelers who will receive higher levels of service.

Customer segments: The main customer segments that MaaS should serve are private users (residents, visitors and tourists) and corporate clients. Regarding private users, different groups of people are served, including commuters, tourists, young people, elderly people, families and students. To reach customers with different needs and characteristics, MaaS should offer different plans with various combinations of transport modes, ticket prices, non-mobility services, etc. For the specific study areas of this paper, the stakeholders' workshops provided evidence on the target customer segments of MaaS. In Greater Manchester and Budapest, young people and professionals were identified as the main customers of MaaS, while in Budapest older people were additionally identified by the stakeholders. Especially young people constitute a significant customer segment for MaaS and are regarded as the most likely group to adopt MaaS (Transport Systems Catapult, 2016), mainly due to their different behavior towards technology, smartphones and car ownership (Kamargianni et al., 2015; Kamargianni and Polydoropoulou, 2013; Klein and Smart, 2017). Corporate customers are also an important customer segment for MaaS, where MaaS services are offered to employees through their employer. Finally, other customer segments of MaaS could include authorities, policy makers, transport planners and other entities interested in acquiring the travel demand management services offered by the MaaS operator.

Channels: This building block includes the way the MaaS operator communicates with and reaches its customer segments to deliver the value proposition. The main channels accessed by customers are the MaaS scheme's website and smartphone application. Through these channels, the customers can be informed about the offered MaaS services (types of modes included, MaaS plans, timetables, ticket prices, etc.), while they can book and purchase their MaaS journey. Other channels to reach customers and attract new clients include media (television, newspaper, etc.) and social media. In addition, the MaaS operator could reach its clients via third-party retailers who could advertise the MaaS scheme on their own website or social media accounts. Finally, since tourists could be an important customer segment of MaaS, an additional channel 
could be the promotion and advertisement via tour operators, hotels, car rental companies, airline companies, etc.

Customer relationships: With regards to customer relationships, the model of personal assistance could be adopted in MaaS. In this way, the customers could be able to communicate with a real customer representative for their assistance mainly through email or call centers. Furthermore, some form of automated services could be developed via the MaaS website and application where the customers could help themselves on a self-service basis. User communities constitute another interface which could be utilized to enhance customer relationships. Through the MaaS website or application, the users could communicate with each other, exchange knowledge and solve each other's problems. A loyalty program could be also established to build customer relationships and maintain customer retention (Magatef and Tomalieh, 2015). Loyalty programs have been widely used by several industries, including airlines, hotels, supermarkets, banks, etc. Finally, co-creation could be used in MaaS, by letting or even inviting customers to write reviews about the MaaS products and plans and, thus, cocreate value for other MaaS customers.

Key resources: To make the business model work, the MaaS operator needs to commit the necessary resources which can be categorized in two types: (i) physical and technological resources, including the scheme's website and mobile application and an integrated information system, including the necessary information regarding the MaaS services, the customers, etc. and (ii) human resources, which comprise of the staff of the MaaS company including IT professionals, analysts, engineers, management team, helpdesk staff etc.).

Cost structure: With regards to the costs of MaaS, these include the initial development of the MaaS scheme (investment cost) and the costs for operating and maintaining the system (operational cost). The investment costs include those associated with the design and the development of the platform and the smartphone application and the brand creation. Regarding the operational costs, they can be further distinguished in fixed and variable costs. Fixed costs constitute the costs that do not change with a difference in the number of customers served and include the amortization of the investment cost, marketing and advertising cost, maintenance cost for the website, the mobile application and the information system, the legal-related costs and the data security and privacy related costs. Variable costs for MaaS include the costs to provide the MaaS services, customer service and support costs, personnel costs and insurance costs.

Revenue streams: The main revenue stream for the MaaS operator is related to the provision and the sales of the MaaS services. However, depending on the form of the MaaS company (i.e. a MaaS company with shareholders or a MaaS partnership with the collaboration of the key partners) different types of revenue streams may occur. In the shareholders' case, the revenue streams for the MaaS operator are related to the direct selling of the MaaS tickets, which are then distributed to the different shareholders of the MaaS company based on a revenue distribution model. In the second circumstance, the MaaS operator acts as a reseller of the tickets of the mobility service providers that collaborate in the MaaS scheme. Thus, the revenues are related to the commission on the MaaS ticket sales agreed between the MaaS operator and the mobility service providers. In general, MaaS tickets can be offered in two ways: (i) subscription for an agreed time period, where it is assumed that end-users pay a weekly, monthly or annual fee and receive bundled transit services from several transport modes, based on their needs, and (ii) pay-as-you-go, where end-users pay separately for each leg of their trip, based on the prices set by each transport service provider (Goodall et al., 2017). Other revenue streams that could evolve in a MaaS scheme are related to advertisement and commissions from non-mobility service providers (i.e. through the contracts conducted with event and entertainment partners). Finally, depending on the legal framework of each city/region, a revenue stream that might be possible is related to subsidization. Based on the MaaS operators' viewpoints in our study areas, revenues are expected as commission on the 


\section{Conclusions and policy recommendations}

A holistic approach in analyzing the business perspective of MaaS has been offered and tailored to three study areas: Budapest, Hungary (BUD); Greater Manchester, United Kingdom (GM); and Luxembourg city, Luxembourg (LUX). With respect to the MaaS business ecosystem, our analysis indicated that mobility service providers (and especially public transport operators) along with other local/regional public authorities are the key actors in MaaS. MaaS cannot be materialized without these actors. Furthermore, the workshops' results indicate that the public transport authorities appear to be the best positioned players to act as the MaaS operators. However, our findings from the in-depth analysis revealed that the public transport authorities in the study areas are unable to undertake such role due to structural and resources constraints.

This paper identified the systemic enablers and barriers regarding MaaS implementation in the three study areas. More specifically, infrastructural, regulatory, societal, political and capacityrelated aspects of MaaS were investigated. Our findings indicate that, in the three study areas, several enablers with variations on their maturity level exist (i.e. electronic tickets, trust between MaaS actors, some open APIs, etc.), while the identified challenges indicate that policy interventions should be carried out by the involved actors (i.e. operators, authorities, societies, policy makers) to support a successful MaaS deployment.

Our analysis also identified regulatory barriers that could hinder the ability of a MaaS operator to apply commercial policies (such as selling discounted tickets and bundled services) to stay competitive. To overcome this issue, the traditional transport-sector policy and regulatory frameworks should be reviewed and adapted to facilitate MaaS implementation.

Another issue is the lack of compatible data formats and standardized APIs among the involved transport operators. Policy makers should establish standards for the data collection, management and sharing so as to support the interoperability of data and APIs feeds and increase the effectiveness of the collaboration between MaaS actors. Given that such standardization process may require investment by the transport operators, policy makers should additionally consider incentivizing investment in this domain.

With respect to infrastructural challenges, it was found that in some areas flexible ticketing and electronic transactions were not available. However, these two elements are key enablers for MaaS. Public transport authorities should exploit the available technological developments and support ticketing innovation on their transport networks. In the same line, the openness of data and APIs feeds should be ensured in each area where MaaS deployment is considered.

Furthermore, our analysis revealed that a number of players in the MaaS ecosystem are important. Collaborative relationships between the public sector (i.e. public transport authorities, public transport operators and municipalities) and the private companies should be fostered. The same applies to the relationships between private companies themselves. Within MaaS private companies should cooperate and compete leveraging competition to create maximum value and promote their businesses. Only if MaaS actors collaborate, will the MaaS potential benefits be delivered to end users and cities.

As mentioned above, the knowledge acquired by the system of innovation framework was utilized to customize the generic business model canvas and develop prototype business models for the three study areas. These business models could be useful for potential MaaS actors (MaaS operators and partners), policy makers, authorities and transport planners who are willing to implement MaaS in cities with similar characteristics. However, special 
consideration should be given when developing a business model for MaaS, given the fact that the landscape of the mobility market is radically changing; new mobility schemes are emerging, new technologies are rapidly being adopted, while we may be experiencing a paradigm shift from ownership to usership.

Finally, the analysis presented here was conducted in three European metropolitan areas and it could be interesting to explore MaaS business models in cities with similar cultures, transportation environment and economies. Further research could include the comparison of our results with findings originated from cities in the United States and Asia. This effort could provide interesting concluding remarks with regards to the impact of the cities' characteristics (i.e. citizens' culture, configuration of the transportation network, power of public transport authorities, dynamics of emerging schemes, etc.) on the development of a prototype business model for MaaS. More attention should be paid as well to the demand side of MaaS, by conducting further research on the impact of MaaS on travel behavior changes, while a SWOT analysis could provide sound insights on the strengths, weaknesses, opportunities and threats a player might face when implementing a MaaS scheme. Future work is currently planned to strengthen our contribution by exploring the impact of MaaS products' costs and, thus, MaaS products' prices on market demand, investigating the market penetration of MaaS in the study areas and the resulting share of the mobility market among the offered services.

\section{Acknowledgments}

This research is part of the Project "MaaS4EU" (End-to-End Approach for Mobility-as-aService tools, business models, enabling framework and evidence for European seamless mobility). This project has received funding from the European Union's Horizon 2020 research and innovation programme under grant agreement No 723176. This publication only reflects the authors' view and the European Union is not liable for any use that may be made of the information contained therein. 


\section{References}

Aapaoja, A., Eckhardt, J., Nykänen, L. (2017). Business models for MaaS. 1st International Conference on Mobility as a Service, 28-29 November 2017, Tampere, Finland.

Amit, R., and Zott, C. (2001). Value creation in e-business. Strategic Management Journal, 22, 493-520.

Arend, R. (2013). The business model: Present and future-beyond a skeumorph. Strategic Organization, 11 (4), 390-402.

ARUP (2018). Mobility-as-a-Service: The value proposition for the public and our urban systems.

Buehler, R., and Pucher, J. (2012). Demand for Public Transport in Germany and the USA: An Analysis of Rider Characteristics, Transport Reviews, 32 (5), 541-567, DOI: 10.1080/01441647.2012.707695.

Burgstaller, S., Flowers, D., Tamberrino, D., Terry, H.P., Yang, Y. (2017). Rethinking Mobility: The 'pay-as-you-go' car: Ride hailing just the start. Equity Research, May 23. Goldman Sachs Group. Accessed 11 Dec. 2018 on: https://orfe.princeton.edu/ alaink/SmartDrivingCars/PDFs/Rethinking\%20Mobility Gol dmanSachsMay2017.pdf

CAR (Center for Automotive Research) (2016). The Impact of New Mobility Services on the Automotive Industry, CAR-Center for Automotive Research, Ann Arbor, 2016.

Christensen, C. M. (1997). Innovator's Dilemma: When new technologies cause great firms to fail. Harvard Business School Press Books.

Christensen, C. M., Raynor, M., Mcdonald, R. (2015). What Is Disruptive Innovation? Harvard Business Review, 93 (12), 44-53.

Currie, G. (2016). Deregulation, franchising, outsourcing and corporatisation in local public transport: International experience. In OECD discussion paper 2016-10 I.T.Forum. Paris, France, prepared for the working group on public transport market organisation and innovation.

DaSilva, C.M., Trkman, P. (2014). Business Model: What It Is and What It Is Not. Long Range Planning, 47, 379-389.

Ebrahimi, S., Sharmeen, F., Meurs, H. (2018). Innovative Business Architectures (BAs) for Mobility as a Service (MaaS) - Exploration, Assessment, and Categorization Using Operational MaaS Cases. Transportation Research Board 97th Annual Meeting, 7-11 January, 2018, Washington DC, United States.

Eckhardt, J., Aapaoja, A., Nykänen, L., Sochor, J. (2017). Mobility as a Service business and operator models, $12^{\text {th }}$ ITS European Congress. Strasbourg, France.

European Commission (EC) (2017a). Smart mobility and services: Expert group report. Luxembourg: Publications Office of the European Union, 2017.

European Commission (EC) (2017b). EU transport in figures-statistical pocketbook. Luxembourg: Publications Office of the European Union.

Goodall, W., Dovey Fishman, T., Bornstein, J., Bonthron, B. (2017). The rise of mobility as a service - Reshaping How Urbanities Get Around. Deloitte Review 20, 112-129.

Hensher, D.A. (2017). Future bus transport contracts under a mobility as a service (MaaS) regime in the digital age: Are they likely to change? Transportation Research Part A 98, $86-96$. 
Hensher, D.A. (2018). Tackling road congestion - What might it look like in the future under a collaborative and connected mobility model? Transport Policy, 66, A1-A8.

Hietanen, S. (2014). 'Mobility as a Service' - the New Transport Model? Eurotransport, 12 (2) ITS \& Transport Management Supplement, 2-4.

Ho, C.Q., Hensher, D.A., Mulley, C., Wong, Y.Z. (2018). Potential uptake and willingness-topay for Mobility as a Service (MaaS): a stated choice study. Transportation Research Part A, 117, 302-318.

Holmberg, P.E., Collado, M., Sarasini, S., Williander, M. (2016). MaaS framework, Final Report of MaaSterplan project (Vinnova).

House H. (2018, June 19). RMI and Uber Team Up to Expand Shared and Electric Mobility. Retrieved from https://rmi.org/rmi-and-uber-team-up-to-expand-shared-and-electricmobility/

Hungarian Central Statistical Office (HCSO) (2011). Population number, population density, Regional Data-Budapest. Accessed on 25 July 2018 from: http://www.ksh.hu/nepszamlalas/tables_regional_01

Jittrapirom, P., Caiati, V., Feneri, A.-M., Ebrahimigharehbaghi, S., Alonso-González, M., Narayan, J. (2017). Mobility as a Service: A Critical Review of Definitions, Assessments of Schemes, and Key Challenges. Urban Planning, 2(2), 13-25.

Jittrapirom, P., Marchau, V., van der Heijden, R., Meurs, H. (2018). Dynamic adaptive policymaking for implementing Mobility-as-a Service (MaaS). Research in Transportation Business \& Management (in press).

Juhász, M., Mátrai, T., Kerényi, L.S. (2014).Changes in travel demand in Budapest during the last 10 years. Transportation Research Procedia 1, 154-164.

Kamargianni, M., Matyas, M., Li, W., Schäfer, A. (2015). Feasibility Study for "Mobility as a Service" concept in London. FS-MaaS Final Deliverable.

Kamargianni, M., Matyas, M. (2017). The Business Ecosystem of Mobility-as-a-Service. 96th Transportation Research Board (TRB) Annual Meeting. Washington DC, 8-12 January 2017.

Kamargianni, M., and Polydoropoulou, A. (2013). Hybrid choice model to investigate effects of teenagers' attitudes toward walking and cycling on mode choice behavior. Transportation Research Record: Journal of the Transportation Research Board 2382, $151-161$

Karlsson, M., Sochor, J., Strömberg, H. (2016). Developing the "Service" in Mobility as a Service: experiences from a field trial of an innovative travel brokerage. Transportation Research Procedia 14, 3265-3273.

Klein, N., Smart, M. (2017). Millennials and car ownership: Less money, fewer cars. Transport Policy 53, 20-29.

Kogut, P., \& Rapacz, A. (2015). Market Analysis. Deliverable D7.5 of the EU-funded project European Cloud Marketplace for Intelligent Mobility (ECIM).

König, D., Eckhardt, J., Aapaoja, A., Sochor, J., Karlsson, M. (2016). Deliverable 3: Business and operator models for MaaS. MAASiFiE project funded by CEDR.

Lane, R., \& McGuire, V. (2014). Door to Door Combined Mobility and the Changing Transit Landscape. A whitepaper prepared for the Transit Leadership Summit, London. 
Li, Y. and Voege, T. (2017). Mobility as a Service (MaaS): Challenges of Implementation and Policy Required. Journal of Transportation Technologies, 7, 95-106. https://doi.org/10.4236/jtts.2017.72007

Litman, T. (2018). Autonomous vehicle implementation predictions: Implications for transport planning. Victoria, BC: Victoria Transport Policy Institute.

Ma, Y., Rong, K., Mangalagiu, D., Thornton, T.F., Zhu, D. (2018). Co-evolution between urban sustainability and business ecosystem innovation: Evidence from the sharing mobility sector in Shanghai. Journal of Cleaner Production 188, 942-953.

MaaSLab (2018). "The MaaS Dictionary". Accessed on 25 July 2018 from: https://www.maaslab.org/reports

Magatef, S.G., and Tomalieh, E.F. (2015). The Impact of Customer Loyalty Programs on Customer Retention. International Journal of Business and Social Science 6, 8(1), 78-93.

Magretta, J. (2002). Why business models matter. Harvard Business Review, 80(5), 86-92.

McKinsey \& Company (2016). Automotive Revolution -Perspective Towards 2030, McKisney \& Company - Advanced Industries.

Morris, M., Schindehutte, M., Allen, J. (2005). The entrepreneur's business model: toward a unified perspective. Journal of Business Research, 58, 726-735.

Mulley, C. (2017). Mobility as a Services (MaaS) - does it have critical mass?. Transport Reviews, 37 (3), 247-251, DOI: 10.1080/01441647.2017.1280932

Mulley, C., and Kronsell, A. (2018). Workshop 7 report: The "uberisation" of public transport and mobility as a service (MaaS): Implications for future mainstream public transport. Research in Transportation Economics (in press).

Mulley, C., Nelson, J.D., Wright, S. (2018). Community transport meets mobility as a service: On the road to a new a flexible future. Research in Transportation Economics (in press).

Nazari, F., Noruzoliaee, M., Mohammadian, A. (2018). Shared versus private mobility: Modeling public interest in autonomous vehicles accounting for latent attitudes. Transportation Research Part C: Emerging Technologies, 97, 456-477.

Nikitas, A., Kougias, I., Alyavina, E., Tchouamou, E.N. (2017). How Can Autonomous and Connected Vehicles, Electromobility, BRT, Hyperloop, Shared Use Mobility and Mobility-As-A-Service Shape Transport Futures for the Context of Smart Cities? Urban Science, 1(36). doi:10.3390/urbansci1040.

Oliver Wyman (2016). Mobility 2040: Staying ahead of disruption.

Organisation for Economic Co-operation and Development (OECD) (2016). International Migration Outlook 2016. OECD Publishing, Paris.

Organisation for Economic Co-operation and Development (OECD) (2018a). Selected indicators for Hungary. Accessed on 14 January 2018 from: https://data.oecd.org/hungary.htm

Organisation for Economic Co-operation and Development (OECD) (2018b). Selected indicators for United Kingdom. Accessed on 14 January 2018 from: https://data.oecd.org/united-kingdom.htm

Organisation for Economic Co-operation and Development (OECD) (2018c). Selected indicators for Luxembourg. Accessed on 14 January 2018 from: https://data.oecd.org/luxembourg.htm 
Osterwalder, A., Pigneur, Y., Tucci, C. (2005). Clarifying Business Models: Origins, Present, and Future of the Concept. Communications of the Association for Information Systems, 16(1), 1-40.

Osterwalder, A., and Pigneur, Y. (2010). Business model generation: a handbook for visionaries, game changers, and challengers. John Wiley \& Sons.

Parilla, J., Trujillo, J. L., Berube, A. (2014). Global Metromonitor 2014: An uncertain recovery. Metropolitan Policy Program, Brookings, Washington, D.C.

Polis (2017). Mobility as a Service: Implications for urban and regional transport. Discussion paper offering the perspective of Polis member cities and regions on Mobility as a Service, Brussels, Belgium.

Pöllänen, J. (2018). Mobility as a Service The End of Car Ownership?[Pdf Slides]. Retrieved from https://www.apta.com/resources/mobility/Documents/TRB\%20MAAS.pdf

Polydoropoulou, A., Pagoni, I., Tsirimpa, A. (2019). Ready for Mobility as a Service? Insights from Stakeholders and End-users. Journal of Travel Behaviour and Society. https://doi.org/10.1016/j.tbs.2018.11.003

Ritala, P., Kraus, S. Bouncken, R.B. (2016) 'Introduction to coopetition and innovation: contemporary topics and future research opportunities', International Journal of Technology Management, 71(1/2), 1-9.

Romanyuk, J. (2018). Mobility as a Service-Hype or the future of transportation? Master's Thesis, Aalto University School of Business, Finland.

Roumboutsos, A., Kapros, S., Vanelslander, T. (2014). Green city logistics: Systems of Innovation to assess the potential of E-vehicles. Research in Transportation Business \& Management 11, 43-52.

Sarasini, S., Sochor, J., Arby, J. (2017). What characterises a sustainable MaaS business model? $1^{\text {st }}$ International Conference on Mobility as a Service, 28-29 November 2017, Tampere, Finland.

Shafer, S., Smith, H., Linder, J. (2005). The power of business models. Business Horizons, 48, 199-207.

Shaheen, A., Stocker, A., Bhattacharyya, A. (2016). Multimobility and Sharing Economy. Transportation Research Circular, E-C210, Transportation Research Board: Washington, D.C.

Smith, G., Sochor, J., Sarasini, S. (2018). Mobility as a service: Comparing developments in Sweden and Finland. Research in Transportation Business \& Management (in press).

Sprei, F. (2018). Disrupting mobility. Energy Research \& Social Science, 37, 238-242.

STATEC (2017). Luxembourg City has a population of 114,090. Accessed on 14 January 2019 from: http://luxembourg.public.lu/en/actualites/2017/01/30-population-vdl/index.html

Teece, D. (2018). Business models and dynamic capabilities. Long Range Planning, 51 (1), 4049.

Transport for Greater Manchester (2018). Transport Statistics Greater Manchester Background Information Section 2016. Data accessed on 19 July 2018 from: https://data.gov.uk/dataset/39cfa67f-0e5a-4bde-a78b-ae7fdf53595b/transport-statisticsgreater-manchester-background-information

Transport Systems Catapult. (2016). Exploring the opportunity for Mobility as a Service in the UK. UK: Transport Systems Catapult. 
Tsirimpa, A., Polydoropoulou, A., Pagoni, I., Tsouros, I. (2018). MaaS Ecosystem Requirements. Deliverable 2.2, MaaS4EU Project.

Utriainen, R., Pöllänen, M. (2018). Review on mobility as a service in scientific publications. Research in Transportation Business \& Management (in press).

Veerapanane, S., Taylor, A., Kaparias, I. (2018). A utility-based model for the evaluation of "Mobility as a Service" applications. 97th Transportation Research Board Annual Meeting, January 7-11, 2018, Washington, D.C., U.S.A.

Veit, D., Clemons, E., Benlian, A., Buxmann, P., Hess, T., Kundisch, D., Leimeister, J.M., Loos, P., Spann, M. (2014). Business Models-An Information Systems Research Agenda. In: Business \& Information Systems Engineering-Research Notes, 1, 45-53.

Wadud, Z., MacKenzie, D., Leiby, P. (2016). Help or hindrance? the travel, energy and carbon impacts of highly automated vehicles. Transportation Research Part A: Policy and Practice, 86, 1-18. http://dx.doi.org/10.1016/j.tra.2015.12.001

Weill, P., Malone, T.W., Apel, T.G. (2011). The Business Models Investors Prefer. MIT Sloan Management Review, 52 (4), 16-19.

Wong, Y.Z., Hensher, D.A., Mulley, C. (2019). Mode-agnostic mobility contracts: identifying broker/aggregator models for delivering mobility as a service (MaaS). Working Paper ITLS-WP-19-01, Institute of Transport and Logistics Studies (ITLS), The University of Sydney Business School, Australia.

Woolthuis, R.K., Lankhuizen, M., Gilsing, V. (2005). A system failure framework for innovation policy design. Technovation 25, 609-619.

Zott, C., Amit, R., \& Massa, L. (2011). The business model: Recent developments and future research. Journal of Management, 37(4), 1019-1042. 